\title{
IDENTIDAD DE GÉNERO, RELACIONES FAMILIARES \\ Y DERECHOS DE NIÑOS, NIÑAS Y ADOLESCENTES. COMENTARIOS AL PROYECTO DE LEY QUE RECONOCE Y DA PROTECCIÓN AL DERECHO A LA IDENTIDAD DE GÉNERO*
}

\author{
NICOLÁs ESPEJO YAKSIC** \\ FABIOLA LATHROP GÓMEZ***
}

RESUMEN: Este artículo se refiere a ciertos aspectos de la identidad de género con ocasión de la reforma que al respecto se discute en nuestro Parlamento. Esta iniciativa implica desafíos tales como no restringir el reconocimiento de este derecho a una cuestión meramente formal sino abordar sus efectos; e incluir expresamente a niñas, niños y adolescentes (NNA) entre sus titulares. Al ser el género un elemento de la identidad de los sujetos, y considerarse su reconocimiento como un derecho fundamental, intereses de terceros no pueden restringir ilegítimamente su ejercicio, sino superando un estricto escrutinio de razonabilidad. Asimismo, sostenemos que este reconocimiento no debe, por sí mismo, alterar las relaciones familiares del beneficiado, como son las derivadas de su matrimonio y/o de su paternidad o maternidad. En especial, entendemos que los NNA pueden y deben ejercer este derecho a la luz de la normativa internacional que consagra el respeto a su interés superior, a su identidad, su derecho a ser oído y a la responsabilidad parental; en este sentido, nos referimos a la presentación de la solicitud en casos de NNA, al procedimiento a que ella puede someterse, y a la reversibilidad del reconocimiento en su caso.

Este texto desarrolla las opiniones vertidas por los autores en la sesión de 2 de julio de 2014 ante la Comisión de Derechos Humanos, Nacionalidad y Ciudadanía del Senado, con ocasión de la discusión del Proyecto de Ley que reconoce y da protección a la identidad de género (Boletín 8924-07). Este trabajo ha sido realizado en el marco del Proyecto Fondecyt Regular "Hacia una reconstrucción del Derecho de Familia: derechos de la Infancia y vida personal", No 1140033.

Fecha de recepción: 30 de octubre de 2014.

Fecha de aceptación: 14 de abril de 2015.

** Doctor en Derecho por la Universidad de Warwick (Inglaterra); Profesor Visitante de la Universidad de Oxford (Inglaterra) y Consultor del Fondo de las Naciones Unidas para la Infancia (UNICEF). Correo electrónico: nicoespejo@gmail.com

*** Doctora en Derecho por la Universidad de Salamanca (España); y Profesora Asociada de Derecho Civil de la Universidad de Chile (CHILe). Correo electrónico: flathrop@derecho. uchile.cl. 
PALABRAS CLAVE: Derecho a la identidad de género - Derechos de los niños, niñas y adolescentes - Reconocimiento de derechos fundamentales - Derechos humanos - Relaciones familiares.

\title{
GENDER IDENTITY, FAMILY RELATIONSHIPS AND RIGHTS OF CHILDREN \& ADOLESCENTS. COMMENTARY ON BILL FOR RECOGNITION AND PROTECTION OF GENDER IDENTITY RIGHTS
}

\begin{abstract}
This essay refers to certain aspects of gender identity with regard to the modifications that are discussed in our Parliament. This initiative implies challenges, such as not restricting the right to a purely formal recognition but also addressing its effects, which explicitly includes children and adolescents among their owners. The gender as an element of identity of individuals, and considering its recognition as a human right, third party interests cannot illegitimately restrict its exercise but surpassing strict scrutiny of reasonableness. Furthermore, we argue that this recognition should not, by itself, alter family relationships benefited, such as those arising from marriage and/or his parentage. In particular, we understand that children and adolescents can and should exercise this right in light of the international law that enshrines respect for their interests, identity, and right to a hearing and parental responsibility. In this sense, we refer to the submission of the request in cases of children and adolescents, the procedure that it may be subjected, and the reversibility of recognition in its case.
\end{abstract}

KEYWORDS: Right to gender identity, children and adolescents rights - recognition of fundamental rights - Human Rights - family relationships.

Sumario. Introducción. 1. Identidad de género y relaciones de familia. 1.1. El derecho al reconocimiento de la identidad de género versus los intereses de terceros. 1.2. Principio de continuidad en las relaciones familiares. 1.2.1. Matrimonio. 1.2.2. Filiación. 2 El derecho del NNA al reconocimiento de su identidad de género. 2.1. Identidad de género y Derecho Internacional de la Infancia y de la Adolescencia. 2.1.1. Interés superior y derechos de los NNA: dos caras de la misma moneda. 2.1.2. Derecho a la identidad de los $N N A$, incluida su identidad de género. 2.1.3. El derecho de los NNA a ser oidos y a ser tomados debidamente en cuenta en toda decisión que les afecta. 2.1.4. El derecho de los padres o representantes legales de los NNA a impar- 
tirles dirección y orientación. 2.2. Reconocimiento y protección del derecho a la identidad de género de los NNA. 2.2.1. Solicitud de reconocimiento de la identidad de género de NNA. 2.2.2. Procedimiento al que se sujetan las solicitudes de reconocimiento de la identidad de género de NNA. 2.2.3. Reversibilidad del reconocimiento de la identidad de género del NNA.

\section{INTRODUCCIÓN}

Este ensayo comenta algunas cuestiones del Proyecto de Ley que reconoce y da protección al derecho a la identidad de género ${ }^{1}$, en lo que respecta a las relaciones de familia y a los derechos de niñas, niños y adolescentes ${ }^{2}$.

En la actualidad, la identidad de género de las personas se reconoce, a falta de legislación especial ${ }^{3}$, autorizando el cambio de nombre y de sexo. Las normas invocadas al respecto son la Ley $\mathrm{N}^{\circ} 17.344$, que autoriza el cambio de nombre y apellidos en los casos que indica (de 1970), y la Ley N4.808 de Registro Civil (de 1943).

La jurisprudencia, aunque tiende a uniformarse en el último tiempo permitiendo el cambio de nombre y sexo sin exigir intervención quirúrgica $^{4}$, presenta casos en que la exige ${ }^{5}$, con lo cual el vacío legal genera

Boletín 8.924-07, Proyecto de Ley que reconoce y da protección al derecho a la identidad de género. 2013. En adelante, "Proyecto".

2 En adelante, "NNA".

3 El propio Registro Civil chileno ha señalado en un Ordinario del año 2010 que: “(...) este servicio informa a los tribunales de justicia que a falta de norma legal corresponde al juez de la causa resolver acerca de la procedencia o improcedencia de la rectificación solicitada". (Ordinario de la Subdirección Jurídica del Servicio de Registro Civil e Identificación N ${ }^{\circ}$ 0013, del 5 de enero del 2010).

4 A efectos de este trabajo analizamos cuarenta causas con sentencia de término. En treinta y tres casos se acogía la solicitud de cambio de nombre y sexo; señalándose en una de ellas que las intervenciones quirúrgicas son un elemento accidental de formación de juicio y no un requisito para acceder a la solicitud (Primer Juzgado Civil de Rancagua, de 16 de agosto de 2011, Rol 419-2010). Por su parte, solo cuatro de ellas rechazaban la petición, y tres la acogían parcialmente (se accedía solo a cambio de nombre por ejemplo). Cabe señalar que entre las sentencias favorables se encuentran dos emanadas de Corte de Apelaciones que revocan fallos de primera instancia que denegaban la solicitud de cambio de nombre y sexo. La primera es de Corte de Apelaciones de Valparaíso, de 23 de julio de 2013, Rol 949-13, que en su considerando décimo señala que "el acceder solo al cambio de nombre sin incluir modificar su sexo, sería discriminatorio para el solicitante, dado que mantener su sexo como femenino le afectaría en su actuación familiar, laboral y social (...)". La segunda es de Corte de Apelaciones de Santiago, de 21 de agosto de 2013, Rol 204-2012, que establece en su considerando sexto que no es posible desconocer la realidad que vive el sujeto y que "a objeto que pueda alcanzar el pleno desarrollo de su personalidad sin discriminación y con respeto a su vida privada como a su honra, se accederá al cambio de sexo (...)."

5 Es el caso de la sentencia del Decimosexto Juzgado Civil de Santiago, Rol 09-2009, de 30 de noviembre de 2009, que indica “(...) Que la solicitante no acompañó ningún certificado médico que acredite que haya sido sometida a una operación de cambio de sexo (...) y que 
inseguridad jurídica. El Proyecto de ley busca dar respuesta a estas cuestiones.

En primer lugar, cabe señalar que se trata de un Proyecto sobre la identidad de género de las personas. En este sentido, de transformarse en ley, sería más holística que la mayoría de las normativas comparadas, que se refieren solo a la rectificación de ciertas partidas de los sujetos ${ }^{6}$. Al respecto, estimamos que si bien el reconocimiento de la identidad de género se concreta principalmente en la modificación de las partidas de identificación, los efectos que esta corrección acarrea desbordan el ámbito registral. De esta forma, al proteger la identidad de género como un derecho humano, esta iniciativa reconocería tal dimensión de la personalidad, desde una perspectiva transversal a todo el ordenamiento jurídico. En efecto, este Proyecto busca proteger al individuo en importantes esferas de sus relaciones sociales; toca a la persona en sus aspectos civiles en general, esto es, en cuanto a su estado civil, derechos de la personalidad, contextos familiares, y vínculos patrimoniales con terceros, entre otras materias.

Estas características del Proyecto implican un doble desafío: no restringirse a un reconocimiento formal, sino abordar sus efectos, en especial en lo que respecta a las relaciones familiares; y, en segundo lugar, no limitarse a la protección de la identidad de género de las personas mayores de edad, sino comprender entre sus titulares a los NNA. A estas cuestiones nos referiremos a continuación.

\section{1) IDENTIDAD DE GÉNERO Y RELACIONES DE FAMILIA}

\section{1.) EL DERECHO AL RECONOCIMIENTO DE LA IDENTIDAD DE GÉNERO VERSUS LOS INTERESES DE TERCEROS}

Como es sabido, la identidad de una persona ${ }^{7}$ importa al ordenamiento jurídico en cuanto esta entra en relaciones con terceros, exterio-

“(...) respecto al cambio de nombre propio (...), resultaría procedente en la medida que el peticionario se acogiera al cambio de sexo, en virtud de lo dispuesto por los artículos $17 \mathrm{y}$ 18 de la Ley 4808.'

$6 \quad$ Es el caso de la Ley española 3/2007, de 15 de marzo, reguladora de la rectificación registral de la mención relativa al sexo de las personas. Excepcionalmente, Argentina cuenta con la Ley No 26.743, que establece el derecho a la identidad de género de las personas, de 2012; y Uruguay con la Ley No 18.620 sobre el derecho a la identidad de género y al cambio de nombre y sexo en documentos identificatorios, de 2009.

7 En esta materia se advierten diversas categorizaciones de la identidad. A efectos de este artículo, asumiremos, siguiendo a Benavente, que la identidad se manifiesta en el contexto inmediato de la persona en dos elementos: el nombre de la persona y el derecho a la propia identidad sexual. El primero es el elemento de identificación frente a los demás, es decir, su identidad personal. El segundo conforma la identidad sexual del sujeto. Compárese: Benavente, Pilar (2013). "Identidad y contexto inmediato de la persona (Identidad perso- 
rizando ciertos aspectos de su individualidad. Tradicionalmente, el sexo y el nombre han sido dos importantes elementos configuradores de la identidad de una persona. Sin embargo, existen otros rasgos esenciales para la individualización del sujeto de derecho en sus relaciones sociales patrimoniales y extrapatrimoniales. En este sentido, el género de una persona es también un elemento de su identidad toda vez que los sujetos se vinculan con otros desde su pertenencia a un género, la cual puede ser exteriorizada y conocida por esos terceros ${ }^{8}$. Así es como la determinación de los elementos de la identidad pueden llegar a importar a terceras personas, sean contratantes o miembros del entorno familiar. Dada la relevancia jurídica que revisten estos elementos como configuradores de la identidad de una persona, los mismos constan en determinados registros administrados por un servicio público especial (el de Registro Civil e Identificación en nuestro país).

En esta parte del ensayo, intentaremos explicar que estos intereses de terceros no pueden restringir ilegítimamente derechos fundamentales del ser humano: cualquier limitación al reconocimiento y ejercicio del derecho a la identidad debe superar un estricto escrutinio de razonabilidad y ser justificadas, en una sociedad democrática, para la consecución de fines pertinentes.

Nos referimos a esta cuestión, pues durante la discusión del Proyecto se han propuesto algunas normas que limitan el reconocimiento de la identidad de género de las personas con el fin de proteger intereses y derechos de otros sujetos involucrados.

En este sentido, y en lo que respecta al ámbito de las relaciones de familia, estimamos injustificado que el reconocimiento de la identidad de género de una persona exija que el sujeto no se encuentre casado o

nal, el nombre de la persona, identidad sexual y su protección)". Anuario de la Facultad de Derecho de la Universidad Autónoma de Madrid, No 17, 105-161 pp., p.107. En este mismo sentido, se ha definido la identidad personal como el "conjunto de atributos y características que permiten individualizar a la persona en sociedad.” Fernández Sessarego, Carlos (1992). Derecho de la Identidad Personal. Buenos Aires: Astrea. p.113.

8 La Comisión Interamericana de Derechos Humanos hace suya la siguiente definición de "expresión de género": "la manifestación externa de los rasgos culturales que permiten identificar a una persona como masculina o femenina conforme a los patrones considerados propios de cada género por una determinada sociedad en un momento histórico determinado." Disponible en [http://www.oas.org/es/cidh/lgtbi/mandato/precisiones.asp] [fecha de visita 7 de marzo de 2015]. A su vez, los Principios de Yogyakarta de 2007 entienden por “identidad de género” lo siguiente: “(...) la 'identidad de género’ se refiere a la vivencia interna e individual del género tal como cada persona la siente profundamente, la cual podría corresponder o no con el sexo asignado al momento del nacimiento, incluyendo la vivencia personal del cuerpo (que podría involucrar la modificación de la apariencia o la función corporal a través de medios médicos, quirúrgicos o de otra índole, siempre que la misma sea libremente escogida) y otras expresiones de género, incluyendo la vestimenta, el modo de hablar y los modales." Este concepto de identidad de género es el que reproduce el Proyecto en su art. 2. 
no tenga descendencia; como asimismo, el dar publicidad a la solicitud de reconocimiento de identidad de género para que posibles terceros involucrados se opongan. En general, en consideración a que el Proyecto reconoce la identidad de género como un derecho humano, estimamos que deben desecharse disposiciones paternalistas que pretendan proteger al propio individuo de las manifestaciones de su identidad de género, revistiendo de formalismos inútiles al proceso de reconocimiento de dicha identidad?.

Estas situaciones podrán, eventualmente, generar una ponderación de principios involucrados en colisiones de derechos; sin embargo, no procede restringir anticipada e injustamente el derecho para asegurar intereses hipotéticos o eventuales. En dicho caso, nos encontraríamos frente a restricciones abiertamente desproporcionadas e ilegítimas, puesto que no se basan en el análisis de una ponderación en el caso concreto ${ }^{10}$.

Al respecto, resulta útil observar la evolución del Derecho Comparado. En un comienzo, Espańa y Alemania restringieron la rectificación de las partidas a los casos en que los solicitantes fueran solteros y estériles, e impidieron que contrajeren matrimonio en el futuro. Sin embargo, con posterioridad, potenciales intereses de terceros fueron cediendo ante la satisfacción del derecho a la identidad de las personas transexuales, de manera de no restringir anticipadamente el reconocimiento del mismo.

Así, a partir del año 2001, la jurisprudencia administrativa española permite contraer matrimonio a quien ha cambiado su sexo ${ }^{11}$. Por su parte, la normativa alemana de 1980 exigía que el peticionario no estuviera casado y que fuera estéril ${ }^{12}$. Paulatinamente, la jurisprudencia constitucional alemana fue declarando inconstitucionales estas exigencias. Así,

$9 \quad$ En Chile, Corral opina lo contrario: "los problemas del transexualismo no cabe enfocarlos con una óptica centrada únicamente en el deseo subjetivo y en la situación aislada del transexual (...). No parece que puedan descuidarse, por ejemplo, los intereses del cónyuge o de los hijos de la persona que sustituye su sexo por el contrario. Tampoco puede ser ignorado o minusvalorado el interés de la comunidad en la preservación de la diferenciación sexual procreativa en el matrimonio y la certeza jurídica en las relaciones conyugales y familiares." Corral, Hernán (2007) "Identidad sexual y transexualismo. Desafíos para el Derecho de la persona y de la familia". Revista de Derecho y Ciencias Penales, No 9, 79-85 pp., p.5.

10 El Tribunal Europeo de Derechos Humanos se ha pronunciado sobre la identidad sexual reconociendo efectos plenos al cambio de sexo, descartando limitaciones a la libertad matrimonial del solicitante. Este tribunal ha señalado que, de lo contrario, se atentaría contra el art. 12 del Convenio Europeo de Derechos Humanos, referido al derecho a contraer matrimonio. Véase sentencia de 11 de julio de 2002. Demanda No 25680/94. "Case I vs. United Kingdom”. Disponible en http://hudoc.echr.coe.int/sites/eng/Pages/search. aspx\#\{“languageisocode":[“ENG"],"documentcollectionid2":[“JUDGMENTS"],"kpda te”:[“2002-07-11T00:00:00.0Z”,”2002-07-11T00:00:00.0Z”],"itemid”:[“001-60595”]\} [fecha de visita 25 de agosto de 2014].

11 Compárese: Benavente, (2013) 131.

12 Esta normativa exigía también intervención quirúrgica; apariencia exterior acorde con el nuevo sexo; haber cumplido 25 ańos de edad y tres ańos de pertenencia al nuevo sexo; y que fuera presumible que el sujeto favorecido con el cambio de sexo no lo modificare en el futuro. 
en el año 2009, a raíz de una sentencia del Tribunal Constitucional de 2008, se dicta una ley que permite el cambio de sexo sin necesidad de ser soltero. Asimismo, en 2011, este Tribunal impide exigir la esterilidad del sujeto hasta que se reforme la normativa en cuestión ${ }^{13}$. Finalmente, el 7 de marzo de 2013 el Legislador alemán dicta una ley que permite indicar como "indeterminado" el sexo del nacido ${ }^{14}$.

\section{2.) PRINCIPIO DE CONTINUIDAD EN LAS RELACIONES FAMILIARES}

El Proyecto es escueto en la regulación de los efectos del reconocimiento de la identidad de género en las relaciones familiares. Cabe señalar que este vacío podría acarrear que el reconocimiento de la identidad de género sea solo una declaración formal. En este sentido, es aconsejable efectuar las adecuaciones normativas necesarias y previsibles al momento de legislar, y más relevante aún lo es el identificar principios que contribuyan a la interpretación e integración normativa.

Al consagrar el que denominaremos principio de continuidad en las relaciones familiares, el Proyecto colabora incipientemente en esa última tarea. En efecto, el Proyecto establece que el reconocimiento de la identidad de género no altera las relaciones familiares del solicitante: las relaciones propias del derecho de familia son inmodificables, las relaciones familiares se mantienen en todos sus órdenes y grados ${ }^{15}$.

Nos parece que esta norma es adecuada en cuanto aclara que las relaciones de familia del individuo a quien se reconoce su identidad de género, en principio, no deben verse afectadas. En este sentido, entre las instituciones que previsiblemente podrían adecuarse o en cuyo funcionamiento podrían surgir colisiones de derechos, están el matrimonio y las relaciones filiales. Abordaremos ambas figuras a la luz del principio de continuidad de las relaciones de familia.

\subsection{1.) Matrimonio}

En cuanto al matrimonio, podrían generarse dos tipos de problemas en torno a su validez. En primer lugar, se ha propuesto que el cambio en la identidad de género pudiera constituir una causal de nulidad matrimonial ${ }^{16}$. Al respecto, en virtud del principio de continuidad, estimamos que

\footnotetext{
13 Para la evolución alemana, véase Von STRITZKY, Johannes (2013) "El Desarrollo de la Protección Jurídica de las Personas Homosexuales, Bisexuales, Transexuales e Intersexuales (LGBT) en Alemania”. Revista General de Derecho Constitucional, No 17, 1-29 pp.

14 Compárese: Benavente, Pilar (2013). "Orientación sexual e identidad de género y relaciones jurídico privadas". Revista General de Derecho Constitucional, No 17, 1-75 pp., p.21.

Art. 8 del Proyecto.

16 Indicación de la Honorable Senadora señora Pérez San Martín.
} 
es posible y perfectamente legítimo que el consorte del solicitante quiera seguir unido por ese vínculo (no obstante la modificación de la identidad de género del otro). No es necesario agregar como nueva causal de nulidad matrimonial el reconocimiento de la identidad de género de uno de los cónyuges: esta persona podría alegar la nulidad conforme al art. 8 no 1 de la Ley de Matrimonio Civilit.

Asimismo, podría sostenerse que el matrimonio existente o el que en el futuro quisiere celebrarse, sería de carácter homosexual. Al respecto, cabe señalar que una vez que el solicitante casado/a cambia de sexo, la partida de su matrimonio reflejaría que este ha sido contraído por personas del mismo sexo. Concebido el matrimonio homosexual como el celebrado por contrayentes del mismo sexo biológico registral, existiría un matrimonio homosexual sobreviniente, independiente de la orientación sexual que ellos tengan ${ }^{18}$. En este caso, podría dejarse sin efecto vía nulidad invocando el art. 8 n 1 de la Ley de Matrimonio Civil, como hemos señalado en el párrafo anterior.

Por su parte, el matrimonio que celebre en el futuro la persona que ha cambiado su identidad de género (ha cambiado su sexo) no debe ser considerado como matrimonio homosexual automáticamente. Ello solo se produciría si el sujeto tiene orientación homosexual, es decir: a) si habiendo cambiado de sexo masculino a femenino, quisiera casarse con alguien de sexo femenino; b) si siendo de sexo femenino, ha pasado a tenerlo masculino y quisiera contraer matrimonio con otro individuo de sexo masculino. En ambos casos, de acuerdo a la legislación actual, no podría contraer matrimonio.

\subsection{2.) Filiación}

En cuanto a las consecuencias que el reconocimiento de la identidad de género pudiera generar en materia de filiación, estimamos que existen dos grandes ámbitos a distinguir: paternidad/maternidad, y efectos de la filiación. Nos referiremos brevemente a ellos.

17 Esta norma establece que: "Falta el consentimiento libre y espontáneo en los siguientes casos: $1^{\circ}$ Si ha habido error acerca de la identidad de la persona del otro contrayente (...)." En efecto, podría sostenerse que al consentir en el matrimonio hubo una falsa representación de la identidad de género del contratante: en realidad, la verdadera identidad de género de este no era la manifestada exteriormente.

18 Esta parece ser la interpretación que el Servicio de Registro Civil e Identificación siguió al permitir, en julio de 2013 , la celebración de un matrimonio de una pareja conformada por un hombre homosexual (inscrito con sexo masculino) y una persona transexual heterosexual que tenía apariencia de hombre pero que tenía un sexo registral femenino. En este caso, dicho Servicio consideró la diferencia de sexo registral y no la orientación sexual ni la identidad de género. La identidad de género de la persona transexual era de hombre y su orientación sexual era heterosexual. Véase http://www.biobiochile.cl/2013/04/12/registrocivil-confirmo-hora-para-matrimonio-entre-personas-del-mismo-sexo.shtml [fecha de visita 25 de agosto de 2014]. 
El acceso a la paternidad/maternidad por naturaleza dependerá de la condición reproductora del solicitante. En caso de no ser posible este tipo de reproducción, entrarán en juego dos grandes instituciones del Derecho de Familia: la adopción y las técnicas de reproducción asistida ${ }^{19}$. La primera está siendo objeto de reforma legislativa ${ }^{20}$. La segunda, no obstante la legitimidad social que ha alcanzado, no se encuentra regulada en nuestro país.

En cuanto a la adopción, en Chile pueden adoptar los matrimonios y las personas solteras, mas no las uniones de hecho. Dicho esto, el sujeto a quien se le ha reconocido su identidad de género, sea soltero o casado, debe poder acceder a la adopción sin discriminaciones de ningún tipo; y el procedimiento de adopción debe sustanciarse conforme a los principios generales de interés superior del niño y de subsidiariedad, entre otros.

Por su parte, si bien la realidad demuestra un creciente acceso a las técnicas de reproducción asistida ${ }^{21}$ (toda vez que incluso el mercado permite conseguir material genético ajeno y provee condiciones de gestación), la desregulación impide en algunos casos que el ser humano que nace de ellas aparezca jurídicamente como hijo/a de los dos padres/madres que ejercen funciones parentales ${ }^{22}$. Esta situación torna francamente inestable el ámbito en que se legisla sobre identidad de género, y pone en riesgo derechos fundamentales del niño.

En cuanto a la forma de enfrentar estos vacíos, existen dos opciones. La primera es discutir sobre filiación y diversidad sexual en general en el contexto de la modificación a la ley de adopción y de creación de una ley de reproducción asistida. Esta alternativa parece más integral, aunque implica postergar el debate sobre la vida familiar de los NNA en contextos de cambio de identidad de género de personas de su familia (hasta que estén dadas las condiciones políticas para ello). La segunda opción es

19 El cambio de la identidad de género no conlleva siempre esterilidad. Dependiendo de si se trata de un hombre o una mujer transexual y la pareja con la cual se puede unir, las posibilidades teóricas de tratamiento son muchas. Al respecto, puede consultarse Álvarez-DíAz, Jorge (2009) "La maternidad de un padre o... la paternidad de una madre? Transexualidad, reproducción asistida, bioética”. Gac. Méd. Méx., Vol. 146, o 2, 151-157 pp., pp.154-155. El autor distingue más de cincuenta combinaciones de tratamiento.

20 Boletín 9119-18. Reforma integral al sistema de adopción en Chile. 2013.

21 En adelante "TRA".

22 Piénsese en el caso de una mujer transexual (ha cambiado su sexo registral de masculino a femenino) de orientación homosexual que vive en pareja con una mujer. La primera es fértil y puede anidar un embrión. La segunda es estéril. El art. 182 del Código Civil señala que son padre y madre la mujer y el varón que se someten a las TRA. En este caso, pese a que la segunda mujer podría desempeñarse como madre, no figuraría como tal en la partida de nacimiento de su hijo/a. Un caso similar es el de un hombre transgénero que siendo padre no biológico del hijo de su cónyuge desea someterse a cirugía de reasignación genital. El hijo había sido concebido por TRA después de ocho años de relación entre la persona transgénero y la madre biológica. Declarado inválido el matrimonio, este padre pide la custodia del niño. El juez considera los especiales lazos emocionales y psicológicos generados entre el padre y el niño (el niño no conocía "otro" padre que el solicitante desde hace seis años) (K.B. v. J.R., 26 Misc. 3d 465, 887 N.Y.S.2d 516 (Sup. Ct. Kings Co., NY 2009). 
efectuar modificaciones con ocasión del reconocimiento de la identidad de género, para asegurar sintonía con las instituciones relacionadas.

Ahora bien, dado que nuestra actual legislación no regula expresamente las familias homoparentales, los hijos ya nacidos de la persona a quien se le ha reconocido su identidad de género figurarían, una vez modificadas las partidas del sujeto y conforme al lenguaje de la normativa vigente, con dos padres o dos madres. En este caso, para que el reconocimiento de la identidad de género guarde sintonía con las instituciones relacionadas, deberían efectuarse ciertas adecuaciones.

Así, el Proyecto podría establecer que la filiación de los hijos en general no esté asociada a las denominaciones culturales de padre $y$ madre sino, por ejemplo, de progenitor A y progenitor B. Otra solución posible es establecer que las partidas evidencien la realidad social y familiar de ese hijo conforme a las denominaciones culturales, esto es, que sea identificado como hijo de dos padres o dos madres. En esta última situación, podría permitirse la figuración de un padre A y un padre B; o de una madre A y una madre B, según el caso.

Como vemos, la discusión sobre filiación y diversidad sexual no ha sido asumida aún por el Legislador chileno. La necesidad de abordar normativamente las nuevas parentalidades surgió al discutir el Acuerdo de Unión Civil promulgado el 13 de abril de 2015 y, desde luego, se hará patente al regular la identidad de género. Esta cuestión se relaciona con la "parentalidad social", es decir, con aquellas situaciones en que ni el progenitor/a biológico/a ni adoptivo/a legalmente reconocido asumen funciones parentales sino que lo hace un "tercero", como podría serlo un adulto/a significativo para el NNA. Esta es una materia que no ha sido abordada integralmente en Chile $^{23}$, a diferencia de la doctrina ${ }^{24}$ y jurisprudencia comparadas ${ }^{25}$.

23 La ley que crea el Acuerdo de Unión Civil incorporó una norma que permite otorgar el cuidado personal de un hijo al conviviente civil de su padre o madre en caso de inhabilidad de estos (es decir, no crea vínculo filiativo formal). En efecto, dicha ley modifica el inciso segundo del art. 226 del Código Civil en los siguientes términos: "En la elección de estas personas se preferirá a los consanguíneos más próximos y, en especial, a los ascendientes; al cónyuge o al conviviente civil del padre o madre, según corresponda”.

24 El desarrollo de las TRA ha permitido distinguir entre las dimensiones biológicas y sociales de la parentalidad, o si se quiere, entre el parentesco (parentage) y la parentalidad ( $p a$ renthood). Compárese: Bainham, Andrew (1999) "Parentage, Parenthood and Parental Responsibility: Subtle, Elusive Yet Important Distinctions”. Bainham, Andrew; Sclater, Schelley D. \& Richards, Martin (Eds.). What is a Parent?: A Socio-Legal Analysis. Hart Publishing, Oxford, Portland Oregon, 25-46 pp.; Choudhry, Shazia and Herring, Jonathan European Human Rights and Family Law (2010) Hart Publishing, Oxford, Portland Oregon, 170-205 pp.; Rivero, Francisco (2010) "De la relación fáctica a la categoría jurídica: la figura del padrastro y madrastra". Revista de Magister y Doctorado en Derecho de Facultad de Derecho de la Universidad de Chile, No4, 163-188 pp.

25 Véase House of Lords, Re G (Children), (2006), UKHL 43, párrafos 34-35 y 43; Tribunal Europeo de Derechos Humanos. 1 de junio de 2004. Demanda No 45582/99. "Case Leb- 
En cuanto a los efectos de la filiación determinada con anterioridad al reconocimiento de la identidad de género de un sujeto, en conformidad al principio de continuidad que hemos mencionado, el sujeto solicitante que tiene descendencia al momento de reconocerse su identidad de género debiera seguir ejerciendo todos sus derechos y deberes parentales. A modo ejemplar, debe continuar proporcionando alimentos o ejerciendo el cuidado personal de que es titular.

A pesar de estas posibles soluciones, otras preguntas quedan abiertas: ¿Puede restringirse automáticamente el régimen de relación directa y regular que se ha establecido a favor de una persona divorciada con hijos, a quien se le ha reconocido su verdadera identidad de género, por el mero hecho de haber modificado su identidad sexual? ¿Puede la aplicación del interés superior del NNA limitar el ejercicio de la identidad de género de ese padre o madre?

En esta materia coincidimos con la jurisprudencia reciente del Tribunal Europeo de Derechos Humanos. En efecto, este Tribunal ha señalado que no es la transexualidad del padre sino la falta de su estabilidad emocional la que puede determinar la restricción del derecho-deber a mantener relaciones directas y regulares con su hijo, así como la efectiva repercusión en este de dicha inestabilidad ${ }^{26}$. En coherencia con la protección de la identidad de género como derecho humano, el cambio de sexo de un progenitor no implica necesariamente la alteración de sus relaciones familiares, sino solo en cuanto realizada la ponderación de principios involucrados, esté justificado y sea proporcionado en el caso específico de que se conozca. A su vez, el criterio central para la determinación de derechos, obligaciones y responsabilidades parentales será siempre el de la satisfacción del interés superior del niño, cuestión que debe determinarse en el caso concreto, y nunca fundarse en estereotipos asociados al género ${ }^{27}$.

bink v. The Netherlands”, 40 EHRR 18, párrafo 37. Disponible en http://hudoc.echr.coe. int/sites/eng/pages/search.aspx?i=001-61799\#\{“itemid”:[“001-61799”]\} [fecha de visita: 25 de agosto de 2014]; y Tribunal Europeo de Derechos Humanos. 26 de mayo de 2004. Demanda 74969/01. "Case Görgülü v. Germany”. Disponible en http://hudoc.echr.coe.int/ sites/eng/pages/search.aspx?i=001-61646\#\{“itemid”:[“001-61646”]\} [fecha de visita: 25 de agosto de 2014].

26 Véase Tribunal Europeo de Derechos Humanos. 30 de noviembre de 2010. Demanda No 35159/09. "Case P.V. vs. Spain”. Disponible en http://hudoc.echr.coe.int/sites/eng/Pages/ search.aspx\#\{“itemid”:[“001-102597”]\} [fecha de visita: 25 de agosto de 2014].

27 En este sentido, Corte IDH, Fondo, Reparaciones y Costas. Sentencia 12 de febrero de 2012, "Caso Atala Riffo y Niñas vs. Chile". Párrs. 109 y 110. Disponible en http://www. corteidh.or.cr/docs/casos/articulos/seriec_239_esp.pdf [fecha de visita: 25 de agosto de 2014]. 


\section{2) EL DERECHO DEL NNA AL RECONOCIMIENTO DE SU IDENTIDAD DE GÉNERO}

Por último, nos referiremos a la situación de los NNA por cuanto estimamos que el Proyecto debe considerarlos como titulares del derecho al reconocimiento de la identidad de género. Cabe señalar que si bien la generalidad del Derecho Comparado permite el cambio de sexo solo a personas mayores de edad, no lo es menos el que en estos países se critique esta exclusión, considerando que los NNA constituyen un colectivo especialmente vulnerable a las discriminaciones por razón de identidad de género $^{28}$.

En todo caso, precisamos que tratándose de NNA solicitantes los estándares de exigencia deben ser elevados en atención a los principios involucrados en su especial situación: beneficencia, interés superior y autonomía. En efecto, en atención a que los NNA se encuentran en etapa de desarrollo, el Estado debe adoptar medidas especiales de protección de sus derechos.

\section{1.) IDENTIDAD DE GÉNERO Y DERECHO INTERNACIONAL DE LA INFANCIA Y DE LA ADOLESCENCIA}

A efectos de definir los estándares normativos pertinentes para la discusión del reconocimiento del derecho a la identidad de género de NNA, resulta fundamental tener a la vista a lo menos cuatro obligaciones específicas que vinculan al Estado de Chile, en conformidad a lo dispuesto por la Convención de Naciones Unidas Sobre los Derechos del Niños ${ }^{29}$.

Estos deberes derivan del reconocimiento de las siguientes circunstancias en que se encuentran los NNA: el derecho que su interés superior sea tenido como consideración primordial en toda decisión (art. $3^{\circ}$ $\mathrm{CDN}$ ); el derecho a que se respete y proteja el derecho a preservar su identidad (art. 80); el derecho a expresar su opinión libremente y a que tales opiniones sean debidamente tomadas en cuenta en función de su edad y madurez; y el respeto que el Estado debe otorgar a quienes ejercen responsabilidad parental o a quienes se encuentran encargados legalmente de impartir dirección y orientación apropiadas a los NNA para que estos últimos, en consonancia con la evolución de sus facultades, puedan ejer-

\footnotetext{
28 Ejemplo de ello es la denominada "Bathroom Bill", aprobada en 2013 por la Asamblea Legislativa del estado de California. Esta ley exige a las escuelas públicas que permitan a los estudiantes transgénero elegir el uso de los baños, vestuarios y equipo de deporte en función de su identidad de género, con independencia del sexo de su nacimiento. Esta ley es mencionada por Benavente, Pilar. (2013). Orientación sexual e identidad. p.3. En adelante, la "CDN".
} 
cer sus derechos $\left(\operatorname{art} .5^{\circ}\right)^{30}$. A continuación nos referiremos a cada uno de estos derechos.

\subsection{1.) Interés superior $y$ derechos de los NNA: dos caras de la misma moneda}

Como es bien sabido, el principio del interés superior del NNA ${ }^{31}$ posee una larga historia jurisprudencial, especialmente en la tradición jurídica angloamericana ${ }^{32}$. En su formulación más acabada, y en la actualidad, el ISN se ha llegado a concebir como la priorización de los derechos (intereses) de los NNA, por sobre otras consideraciones (inclusive, otros derechos) ${ }^{33}$. En otras palabras, el ISN no busca determinar qué es

$30 \quad$ "Artículo 3

1. En todas las medidas concernientes a los niños que tomen las instituciones públicas o privadas de bienestar social, los tribunales, las autoridades administrativas o los órganos legislativos, una consideración primordial a que se atenderá será el interés superior del niño.

2. Los Estados Partes se comprometen a asegurar al niño la protección y el cuidado que sean necesarios para su bienestar, teniendo en cuenta los derechos y deberes de sus padres, tutores $u$ otras personas responsables de él ante la ley y, con ese fin, tomarán todas las medidas legislativas y administrativas adecuadas.

3. Los Estados Partes se asegurarán de que las instituciones, servicios y establecimientos encargados del cuidado o la protección de los niños cumplan las normas establecidas por las autoridades competentes, especialmente en materia de seguridad, sanidad, número y competencia de su personal, así como en relación con la existencia de una supervisión adecuada".

"Artículo 8

1. Los Estados Partes se comprometen a respetar el derecho del niño a preservar su identidad, incluidos la nacionalidad, el nombre y las relaciones familiares de conformidad con la ley $\mathrm{sin}$ injerencias ilícitas.

2. Cuando un niño sea privado ilegalmente de algunos de los elementos de su identidad o de todos ellos, los Estados Partes deberán prestar la asistencia y protección apropiadas con miras a restablecer rápidamente su identidad".

"Artículo 12

1. Los Estados Partes garantizarán al niño que esté en condiciones de formarse un juicio propio el derecho de expresar su opinión libremente en todos los asuntos que afectan al niño, teniéndose debidamente en cuenta las opiniones del niño, en función de la edad y madurez del niño.

2. Con tal fin, se dará en particular al niño oportunidad de ser escuchado, en todo procedimiento judicial o administrativo que afecte al niño, ya sea directamente o por medio de un representante o de un órgano apropiado, en consonancia con las normas de procedimiento de la ley nacional".

"Artículo 5

Los Estados Partes respetarán las responsabilidades, los derechos y los deberes de los padres o, en su caso, de los miembros de la familia ampliada o de la comunidad, según establezca la costumbre local, de los tutores u otras personas encargadas legalmente del niño de impartirle, en consonancia con la evolución de sus facultades, dirección y orientación apropiadas para que el niño ejerza los derechos reconocidos en la presente Convención".

31 En adelante "ISN".

32 Para el caso de los Estados Unidos de América, "Chaspky v Wood” (1881) 26 Kan. 650. Para el caso de Gran Bretaña, "Re McGrath (Infants)" [1883] 1 Ch 143; "F v F" [1902] 1 Ch 688 y; "Ward v Laverty and Another" [1925] AC 101.

33 Compárese: EexelaAr. John (2005) "Deciding for Children". 7 Australian Journal of Professional and Applied Ethics, pp. 66-82. 
lo que la justicia considera en cada caso sino, en cambio, qué es lo que demandan específicamente los derechos de los NNA en cada situación concreta $^{34}$. Así entendido, el ISN pasa a ser un principio elemental para la consecución de dos fines: a) respetar, con carácter prioritario, los derechos de los niños y; b) incluir otros derechos o intereses en el juicio de ponderación, pero en base a una regla de prioridad a favor de los derechos de los niños.

En su más reciente recapitulación respecto de la naturaleza, composición y efectos del ISN, el Comité de Derechos del Niño de las Naciones Unidas $^{35}$ ha identificado la triple caracterización de este principio, en cuanto derecho sustantivo, principio y norma de procedimiento ${ }^{36}$. En otras palabras, del ISN se deriva un derecho sustantivo, del cual surge la obligación correlativa del Estado de garantizar que el interés superior del NNA se integre de manera adecuada y se aplique sistemáticamente en todas las medidas de las instituciones públicas, en especial en todas las medidas de ejecución y los procedimientos administrativos y judiciales que afectan directa o indirectamente a los $\mathrm{NNA}^{37}$. Del mismo ISN se deriva un principio jurídico interpretativo del que se colige la obligación de velar por que todas las decisiones judiciales y administrativas, las políticas y la legislación relacionadas con los niños dejen patente que el interés superior de estos ha sido una consideración primordial (lo que incluye explicar cómo se ha examinado y evaluado el ISN, y la importancia que se le ha atribuido en la decisión) ${ }^{38}$. Finalmente, el ISN importa una norma de procedimiento que genera la obligación de garantizar que el interés del NNA sea evaluado y que constituya una consideración primordial en las decisiones y medidas adoptadas, inclusive por el sector privado, incluidos los proveedores de servicios, o cualquier otra entidad o institución privadas que tomen decisiones que conciernan o afecten a un NNA ${ }^{39}$.

\subsection{2.) Derecho a la identidad de los NNA, incluida su identidad de género}

A la luz de las obligaciones mencionadas, resulta claro que a los NNA se les debe reconocer todos sus derechos, incluidos el derecho a su

34 Véase S (BD) v S (DJ)” (Infants: Care and Consent) [1977] 1 A11 ER 656; y "Re K" (Minors) (Wardship: Care and Control) [1977] 1 A11 ER 647.

35 En adelante, "el Comité".

36 Comité de Derechos del Niño, Observación general No 14 "Sobre el derecho del niño a que su interés superior sea una consideración primordial (artículo 3, párrafo 1), CRC/C/GC/14, 29 de mayo de 2013, Párr. 6.

37 Comité de Derechos del Niño, Observación general 14, Párr. 14, letra a).

38 Comité de Derechos del Niño, Observación general 14, Párr. 14, letra b).

39 Comité de Derechos del Niño, Observación general 14, Párr. 14, letra c). 
propia identidad. Respecto de este derecho en particular, el Comité ha indicado recientemente que:

"La identidad del niño abarca características como el sexo, la orientación sexual, el origen nacional, la religión y las creencias, la identidad cultural y la personalidad. Aunque los niños y los jóvenes comparten las necesidades universales básicas, la expresión de esas necesidades depende de una amplia gama de aspectos personales, físicos, sociales y culturales, incluida la evolución de sus facultades. El derecho del niño a preservar su identidad está garantizado por la Convención (Art. 80) y debe ser respetado y tenido en cuenta al evaluar el interés superior del niño"'o.

Así entendido, el derecho a la identidad de los NNA no solo cubre aspectos vinculados a su nombre, nacionalidad u origen familiar. La identidad es la condición de un ser una persona identificable, tanto como un individuo único y separado, tanto como miembro de un determinado grupo $^{41}$. En este sentido, y a pesar de no indicarlo de modo expreso en su art. $8^{\circ}$, el derecho a la identidad de los NNA comprende también su historia personal desde el nacimiento, su raza, cultura, religión, lengua, apariencia física, habilidades, identidad de género y orientación sexual ${ }^{42}$. Como ha señalado la Corte Interamericana de Derechos Humanos “(...) la identidad personal está íntimamente ligada a la persona en su individualidad específica y vida privada, sustentadas ambas en una experiencia histórica y biológica, así como en la forma en que se relaciona dicho individuo con los demás, a través del desarrollo de vínculos en el plano familiar y social. Es por ello que la identidad, si bien no es un derecho exclusivo de los niños y niñas, entraña una importancia especial durante la niñez (...)"43.

Esta interpretación extensiva del derecho a la identidad de los NNA no solo resulta compatible con la interpretación derivada de la propia $\mathrm{CDN}$, sino también con las normas, principios, tratados y demás documentos internacionales que regulan el derecho a la identidad y el principio de no discriminación ${ }^{44}$. Lo anterior resulta fundamental, toda vez que

40 Comité de los Derechos del Niño, Observación general 14, Párr. 55.

41 Compárese: Jenkins, R. (2004) Social Identity, London: Routledge, 218 pp.

42 Compárese: Newell, P. and Hodgkin, R. (2008). Implementation Handbook for the Convention on the Rights of the Child, 3rd. Edition, Suiza. UNICEF. 206 pp., p. 115.

Corte IDH, Fondo, Reparaciones y Costas. Sentencia de 27 de abril de 2012, "Caso Forneron e hija vs. Argentina”. Párr. 123. Disponible en http://www.corteidh.or.cr/docs/casos/ articulos/seriec_242_esp.pdf [fecha de visita: 25 de agosto de 2014].

44 Compárese, entre otros: Consejo de Derechos Humanos de Naciones Unidas. Derechos Humanos, orientación sexual e identidad de género, A/HRC/RES/17/19, de 14 de julio 2011; Informe del Alto Comisionado de las Naciones Unidas para los Derechos Humanos. Leyes y prácticas discriminatorias y actos de violencia cometidos contra personas por su orientación sexual e identidad de género, fue aprobado el 17 de noviembre de 2011, presentado ante el Consejo de Derechos Humanos en el $19^{\circ}$ período de sesiones, A/HRC/19/41; Comisión Interamericana de Derechos Humanos (CIDH), Estudio elaborado por la Comisión Intera- 
los derechos de los NNA no constituyen derechos aislados de los demás derechos humanos, sino parte integrante de los mismos, con una dimensión de protección integral reforzada ${ }^{45}$.

\subsection{3.) El derecho de los NNA a ser oídos y a ser tomados debidamente en cuenta en toda decisión que les afecta}

El art. 12 de la CDN establece el derecho de cada niño a expresar su opinión libremente en todos los asuntos que lo afectan y el subsiguiente derecho a que esas opiniones se tengan debidamente en cuenta en función de su edad y madurez. Recae así sobre los Estados partes la clara obligación jurídica de reconocer ese derecho y garantizar su observancia escuchando las opiniones del NNA y teniéndolas debidamente en cuenta. Tal obligación supone que los Estados partes, con respecto a su respectivo sistema judicial, deben garantizar directamente ese derecho o adoptar o revisar leyes para que el NNA pueda disfrutarlo plenamente.

Como ha indicado el Comité, el art. 12 de la CDN pone de manifiesto que el NNA tiene derechos que ejercen influencia en su vida, que no son únicamente los derechos derivados de su vulnerabilidad (protección) o su dependencia respecto de los adultos (provisión). La CDN reconoce al niño como sujeto de derechos, y la ratificación casi universal de este instrumento internacional por los Estados partes pone de relieve esta condición del niño, que está expresada claramente en el mencionado art. 12 de la $\mathrm{CDN}^{46}$. En otras palabras, el derecho de los NNA a ser oídos y a ser tomados en cuenta es un reconocimiento formal de la idea que los NNA no son meros objetos de protección, sino también titulares de derechos, personas con intereses morales que siempre deben ser considerados en toda materia que les afecte. De lo anterior se colige que no puede protegerse el ISN si la opinión de los NNA no es tomada en cuenta en el proceso de determinación de sus derechos ${ }^{47}$.

Respecto de la capacidad de los NNA para expresar sus opiniones, debe tenerse en cuenta que la expresión "que esté en condiciones de formarse un juicio propio" no debe verse como una limitación, sino como

mericana de Derechos Humanos "CIDH" en cumplimiento de la resolución AG/RES. 2653 (XLI-O/11): Derechos Humanos, Orientación Sexual e Identidad de Género, 23 de abril de 2012; Asamblea General de la Organización de los Estados Americanos (OEA), AG/RES. 2807 (XLIII-O/13) aprobada el 6 de junio de 2013.

45 Preámbulo de la Convención de Naciones Unidas Sobre los Derechos del Niño.

46 Comité de los Derechos del Niño, Observación General 12 "El derecho del niño a ser escuchado", 20 de julio de 2009, CRC/C/CG/12, Párr. 18.

47 Compárese: Couso, Jaime. (2006) "El Niño como Sujeto de Derechos y la Nueva Justicia de Familia. Interés Superior del Niño, Autonomía Progresiva y Derecho a Ser Oído”. Revista de Derechos del Niño. No Tres y Cuatro. Santiago de Chile: UNICEF, 145-166 pp., p. 147 . 
una obligación para los Estados partes de evaluar la capacidad del NNA de formarse una opinión autónoma en la mayor medida posible. Esto significa que los Estados partes no pueden partir de la premisa de que un NNA es incapaz de expresar sus propias opiniones. Al contrario, los Estados partes deben dar por supuesto que el NNA tiene capacidad para formarse sus propias opiniones y reconocer que tiene derecho a expresarlas; no corresponde al NNA probar primero que tiene esa capacidad ${ }^{48}$.

En relación a la expresión tener "debidamente en cuenta las opiniones del niño, en función de la edad y madurez del niño", el Comité ha precisado que el art. 12 de la CDN deja claro que la edad en sí misma no puede determinar la trascendencia de las opiniones del NNA. Los niveles de comprensión de los NNA no van ligados de manera uniforme a su edad biológica. Por ese motivo, las opiniones del NNA tienen que evaluarse mediante un examen caso por caso ${ }^{49}$. A su vez, y en relación a la idea de "madurez", el mismo Comité ha remarcado que tal expresión hace referencia a la capacidad de comprender y evaluar las consecuencias de un asunto determinado, por lo que debe tomarse en consideración al determinar la capacidad de cada niño. En el contexto del art. 12 de la CDN, madurez refiere a la capacidad de un NNA para expresar sus opiniones sobre las cuestiones, de forma razonable e independiente. Y toda vez que los efectos del asunto en el NNA también deben tenerse en consideración, cuanto mayores sean los efectos del resultado en la vida del NNA, más importante será la correcta evaluación de su madurez ${ }^{50}$.

Finalmente, toda aplicación correcta del derecho de los NNA a ser oídos y tomados debidamente en cuenta, debe prestar atención a la noción de la evolución de sus facultades y a la dirección y orientación que proporcionen los padres. Es decir, el peso específico de la opinión del NNA en la decisión final a su respecto, será siempre función de: a) su capacidad para expresar sus opiniones sobre las cuestiones de forma razonable e independiente y; b) de la deferencia que el Estado debe demostrar al considerar el rol que juegan quienes ejercen funciones primarias de dirección y orientación, en el ejercicio de los derechos de los $\mathrm{NNA}^{51}$.

\subsection{4.) El derecho de los padres o representantes legales de los NNA a impartirles dirección y orientación}

$\mathrm{El}$ art. $5^{\circ}$ de la $\mathrm{CDN}$ reconoce las responsabilidades, derechos y deberes de los padres, o de quienes detenten responsabilidad legal sobre los NNA, de impartirles, en consonancia con la evolución de sus facultades,

\footnotetext{
48 Comité de los Derechos del Niño, Observación General 12, Párr. 20.

49 Comité de los Derechos del Niño, Observación General 12, Párr. 29.

50 Comité de los Derechos del Niño, Observación General 12, Párr. 30.

51 Comité de los Derechos del Niño, Observación General 12, Párr. 31.
} 
dirección y orientación apropiadas para que los NNA ejerzan los derechos reconocidos en la $\mathrm{CDN}^{52}$.

Esta norma no debe ser entendida como la concesión de derechos plenos a los padres o representantes legales de los NNA sobre esos mismos NNA. Lo que la CDN hace, más bien, es reconocer la primacía de la responsabilidad parental respecto de la responsabilidad del Estado. Es decir, dado que los padres o representantes legales tienen un deber u obligación de actuar responsablemente en el desarrollo de los derechos de los niños, pueden oponer tal rol preferente a una intervención no justificada de modo estricto por el Estado (como en aquellos casos en que los derechos de los NNA se puedan ver gravemente amenazados o violados).

Por tanto, lo que consagra el art. $5^{\circ}$ de la $C D N$ es un derecho que los padres o representantes legales de los NNA ejercen en contra del Estado y no en contra de los propios $\mathrm{NNA}^{53}$. Tal posición privilegiada se deriva, a su vez, de su responsabilidad en actuar en interés del NNA, y no, como mal podría entenderse, en que los padres tienen derechos sobre sus hijos ${ }^{54}$.

Ahora bien, y una vez determinado quien ejerce preferentemente las funciones guía y orientación de los NNA (responsabilidad parental), resulta indispensable precisar cómo es que tal responsabilidad debe ser ejercida. En esta materia, nuevamente el Comité provee de una guía fundamental para la interpretación. Así, en su Observación General No 12, indica:

"El artículo 5 de la Convención establece que los Estados partes respetarán las responsabilidades, los derechos y los deberes de los padres, los tutores $o$ los miembros de la familia ampliada o de la comunidad, según establezca la costumbre local, de impartir dirección y orientación al niño en su ejercicio de los derechos reconocidos en la Convención. Por consiguiente, el niño tiene derecho a recibir dirección y orientación, que tienen que compensar la falta de conocimientos, experiencia y comprensión del niño y estar en consonancia con la evolución de sus facultades, como se establece en ese articulo. Cuantas más cosas sepa, haya experimentado y comprenda el niño, más deben los padres, tutores $u$ otras personas legalmente responsables del niño transformar la dirección y orientación en recordatorios y consejos y, más adelante, en un intercambio en pie de igualdad. Esta transformación no tendrá lugar en un punto fijo del desarrollo del niño, sino que se producirá paulatinamente a medida que se alienta al niño a aportar sus opiniones.

\footnotetext{
52 Estas responsabilidades, derechos y deberes deben ejercerse en conformidad al principio de corresponsabilidad parental entre padres y madres, en virtud de lo dispuesto por el art. 18 de la CDN.

53 Compárese: MacDonald QC, Alastair. (2011) The Rights of the Child: Law and Practice, Bristol: Family Law. 1232 pp., p. 460.

54 Compárese: Newell, P. and Hodgkin, R. (2008) p. 76.
} 
Esta condición se ve reafirmada por el artículo 12 de la Convención, que estipula que deberán tenerse debidamente en cuenta las opiniones del niño, siempre que el niño esté en condiciones de formarse un juicio propio. En otras palabras, a medida que los niños adquieren facultades tienen derecho a asumir un nivel cada vez mayor de responsabilidad respecto de la regulación de los asuntos que los afectan" 55 .

En consecuencia, la responsabilidad parental presupone no solo el ejercicio privilegiado de las funciones de guía y orientación de los padres o representantes legales de los NNA en el curso del progresivo desarrollo de sus derechos. En cuanto una institución propia derivada del Derecho de Infancia, la responsabilidad parental presupone siempre el que dicha función se ejerza de un modo compatible con el progresivo desarrollo de la autonomía de los NNA. La responsabilidad parental es, en otras palabras, una posición de privilegio que el Derecho reconoce a ciertos adultos para que guíen y orienten a los NNA, en consonancia con la evolución de sus facultades, para el ejercicio pleno de los derechos de esos niños.

\section{2.) ReCONOCIMIENTO Y PROTECCIÓN DEL DERECHO A LA IDENTIDAD DE GÉNERO DE LOS NNA}

A la luz de lo señalado anteriormente, consideramos esencial que el Legislador reconozca formal y explícitamente el derecho de los NNA a su identidad de género. Esta forma de reconocimiento se deriva de la constatación que los NNA son titulares de todos los derechos humanos, incluidos el derecho a su identidad. No reconocer este derecho fundamental a los menores de edad implicaría una distinción no justificada, y en este sentido discriminatoria, entre adultos y NNA en el ejercicio de sus derechos de la personalidad.

Chile se encuentra avanzando en un proceso de progresivo reconocimiento formal y material de los derechos de los NNA. La iniciativa que comentamos en este ensayo debiera ser vista también como parte integrante de este proceso y como un ejemplo claro del compromiso del Legislador por materializar los derechos de la Infancia.

A continuación nos referiremos a tres aspectos que nos parecen relevantes para la discusión sobre la identidad de género de NNA, estos son: solicitud de reconocimiento por parte del propio NNA, procedimiento a que ella se sujeta, reversibilidad de la rectificación.

55 Comité de los Derechos del Niño, Observación General 12, Párrs. 84-85. En el mismo sentido, Comité de Derechos del Niño, Observación general No 5 "Sobre las medidas generales de aplicación de la Convención sobre los Derechos del Niño (artículos 4 y 42 y párrafo 6 del artículo 44)", 27 de noviembre de 2003, CRC/GC/2003/5. 


\subsection{1.) Solicitud de reconocimiento de la identidad de género de NNA}

Es importante que el Proyecto reconozca el poder procesal de los NNA para solicitar directamente el reconocimiento de su identidad de género. En este sentido, debe entenderse que la solicitud hecha por un adulto debe ser siempre considerada como una forma de facilitar la interposición directa por parte del NNA, y no como una acción independiente. Este punto parece ser considerado debidamente en una de las indicaciones presentadas al Proyecto, al indicar que la solicitud también "podrá ser efectuada a través de sus representantes legales o quien lo tenga bajo cuidado, y con el expreso consentimiento del niño" 56 .

Con todo, y para reforzar el sentido del ejercicio autónomo del derecho por el propio titular, estimamos que debe alterarse el orden de presentación de quienes formulan la solicitud. Así, debe indicarse, en primer término, que la petición puede ser hecha personalmente por el NNA; para luego señalar la posibilidad de que tal solicitud se pueda realizar a través de sus representantes legales o de quien lo tenga bajo su cuidado.

Asimismo, toda vez que, tal y como se ha indicado, todos los derechos reconocidos a los NNA, incluidos el derecho a la identidad y el derecho a ser oído, no establecen un límite de edad formal sino que se sujetan más bien a criterios de determinación de madurez, parece adecuado que el Legislador no fije una edad de corte para el ejercicio de este derecho. Esto es, el derecho a solicitar las rectificaciones respectivas debe ser reconocido a todos los NNA. Si es que el niño o niña es muy pequeño/a, ese derecho debiera ser ejercido a través de su representante legal o de quien lo tenga bajo cuidado. Será luego el tribunal el que determine la suficiencia de la justificación dada en la solicitud, después de escuchar al NNA, para adjudicar definitivamente el derecho, y basado siempre en el interés superior del NNA.

En virtud de lo anterior, y a efectos de dar contenido preciso a la idea de verificar la madurez de la solicitud y su peso específico en la decisión final, sería recomendable que ella fuese debidamente fundada. Es decir, la solicitud hecha por el NNA debiera explicitar los fundamentos que motivan la petición, a objeto de determinar que el NNA comprende y evalúa las implicancias de su petición, así como si ha actuado de manera libre o autónoma. Verificadas estas condiciones, el Juez de Familia debiera aceptar la solicitud, incluso con independencia de la opinión divergente de los adultos responsables o de quienes lo tengan bajo su cuidado.

Como hemos señalado con anterioridad, una vez que el NNA alcanza el umbral justificado de su autonomía actual (razona, justifica, entien-

56 Indicación de la Honorable Senadora señora Pérez San Martín. 
de), el rol de los adultos responsables disminuye o se transforma desde la guía de sus decisiones, hacia la orientación y acompañamiento de las mismas.

\subsection{2.) Procedimiento al que se sujetan las solicitudes de reconocimiento de la identidad de género de NNA}

En cuanto al procedimiento conforme al cual debe conocerse la solicitud reconocimiento de la identidad de género (para adultos), estimamos que debe ser administrativo. Son varias las razones que justifican esta opinión: a) a este ámbito se entregan las cuestiones relacionadas con la identificación de las personas; b) el ámbito administrativo garantiza adecuadamente la intimidad del solicitante; c) no resulta pertinente judicializar $a$ priori estos aspectos 57 .

En este sentido, cabe señalar que los eventuales intereses de terceros quedarían a resguardo con la registración civil que previene la ley en general y el acceso, en cuanto proceda, a los datos personales del individuo (por ejemplo, en situaciones que requieran reconstruir la historia clínica del solicitante). Por otro lado, el Proyecto prevé una norma de índole penal que castiga conductas dolosas que, eventualmente, pudieran perjudicar intereses de terceros.

Sin embargo, en el caso de solicitudes realizadas por NNA, parece aconsejable que la ley determine como competente para conocer de esta materia, al Juez de Familia del lugar donde tenga domicilio el NNA, y en base a las disposiciones sobre actos judiciales no contenciosos ${ }^{58}$.

A su vez, estimamos apropiado derivar el asunto a un procedimiento contencioso, dentro del mismo Tribunal de Familia, cuando exista conflicto de intereses entre el NNA que ha solicitado el reconocimiento de su identidad y las personas que lo representen o lo tengan bajo su cuidado. En efecto, si la edad y madurez del NNA no le permitieran prestar un consentimiento especialmente informado sobre los efectos del cambio en

57 En el Derecho Comparado, países como Uruguay, Holanda, Italia y Alemania, exigen la intervención judicial. En otros, como Suecia, Argentina y España, el procedimiento es administrativo. Compárese: Medina, Graciela (2012) “Comentario exegético a la Ley de Identidad de Género", La Ley, mayo, 45-57 pp., p.51.

58 En el Derecho argentino se ha señalado que es prudente que sea el juez quien otorgue la autorización para la realización de cirugías a practicarse en el niño; por tratarse de intervenciones de altísimo riesgo, irreversibles, y que comprometen la salud reproductiva. Deben ponderarse prudentemente los riesgos previsibles y los beneficios esperables, de forma de consentir la intervención cuando prevalezcan los beneficios esperables respecto de los potenciales riesgos. Se trataría de una manifestación de "paternalismo justificado", considerando que se trata de una cuestión en la que el Estado sí debe injerir para garantizar una verdadera tutela judicial efectiva de los derechos del NNA. Compárese: Fernández, Silvia (2012) "La realización del proyecto de vida autorreferencial. Los principios de autonomía y desjudicialización”. La Ley, 13-25 pp., p.25. 
su identidad de género, el juez con competencia en materias de familia podría estar llamado a efectuar la ponderación de principios involucrados.

En este sentido, por ejemplo, la Corte Constitucional de Colombia se ha referido a la ponderación de los principios de autonomía y beneficencia en casos de NNA transexuales, estableciendo que deben considerarse los siguientes elementos: a) urgencia e importancia del tratamiento para el interés del NNA; b) riesgo e intensidad del impacto del tratamiento sobre la autonomía actual y futura del NNA; c) edad y madurez del NNA ${ }^{59}$.

Respecto de la representación del NNA en dicho procedimiento no contencioso, estimamos innecesario considerar de plano la participación del curador ad litem. Si la ley obliga a que la solicitud hecha por el NNA se funde debidamente, y teniendo en cuenta la obligación del juez de oír al NNA, no debiera contemplar como imperativa la intervención de un tercero (curador ad litem) que vele por los supuestos de reconocimiento del derecho del NNA. Distinta es la cuestión en caso que, por oposición del adulto responsable o de quien lo tenga bajo cuidado, el asunto se conociese por vía contenciosa. En este caso, pudiera ser pertinente la presencia de tal tercero independiente que cautele los intereses del NNA en el procedimiento. En todo caso, dicho curador ad litem debiera contar con la experticia, tiempo y calidad requerida para la representación de los intereses (derechos) independientes del NNA, cosa que el sistema actual no garantiza.

\subsection{3.) Reversibilidad del reconocimiento de la identidad de género del NNA}

Al definirse la identidad de género como una vivencia interna, y considerando que esta puede variar en el tiempo, consideramos que debiera revisarse la restricción que efectúa el Proyecto en cuanto a la rectificación de las partidas a una sola vez, especialmente tratándose de NNA solicitantes.

Un principio fundamental en materia de autonomía progresiva de los NNA es el de Revisibilidad. Los NNA toman decisiones que pueden justificarse razonadamente, en el contexto del desarrollo dinámico de su autonomía de la voluntad. Sin perjuicio de lo anterior, es fundamental considerar la posibilidad de que los NNA revisen sus decisiones, modificando cuantas veces sea necesario aquellos aspectos que consideran fundamentales en sus vidas. Los NNA pueden equivocarse, y es deber del Estado y de la familia generar espacios propicios para que esos errores no generen efectos permanentes, cuando ello sea evitable.

\footnotetext{
59 Sentencias T-551 de 1999 (fundamento 8) y T-1025 de 2002 (fundamento 7). Citadas en Bernal, Julia (2011). "Estados intersexuales en menores de edad: los principios de autonomía y beneficencia”, Revista de Derecho, No 36, 53-85 pp., p.70.
} 
Así, a la luz del principio de Revisibilidad, parece adecuado reconocer la posibilidad que el NNA, tanto antes de cumplir los 18 ańos de edad como cuando se transforma en mayor de edad, solicite nuevamente el reconocimiento de su identidad de género mediante una nueva rectificación de sus partidas.

En este sentido, sostenemos que no se justifica establecer el límite de una sola nueva rectificación por parte del NNA, antes de cumplir los 18 años de edad. El criterio determinante debiera ser el de "solicitud debidamente fundada" y, en virtud de ese mérito, el Juez de Familia debiera acoger o rechazar la solicitud.

Por último, tratándose de NNA que han cumplido los 18 años de edad y que como adultos estimen pertinente solicitar una nueva rectificación, no nos parece adecuado fijar un límite expreso de un año desde la mayoría de edad, para hacerlo. La definición final de aspectos fundamentales del proceso de autodeterminación de la identidad de género constituye un proceso que se extiende razonablemente más allá de los 18 ańos de edad y que se encuentra sujeto a una serie de variables dinámicas. Nuevamente, el criterio rector acá debiera ser el de justificación de la solicitud.

\section{BIBLIOGRAFÍA CITADA}

- Alto comisionado de las Naciones Unidas para los Derechos Humanos. Leyes y prácticas discriminatorias y actos de violencia cometidos contra personas por su orientación sexual e identidad de género, aprobado el 17 de noviembre de 2011, presentado ante el Consejo de Derechos Humanos en el $19^{\circ}$ período de sesiones, A/ $\mathrm{HRC} / 19 / 41$.

- Álvarez-Díaz, Jorge (2009) "La maternidad de un padre o... la paternidad de una madre? Transexualidad, reproducción asistida, bioética”. Gac. Méd. Méx., Vol. 146, No 2, 151-157 pp., pp.154155.

- Asamblea general De la organización de los estados AMERICANOS (OEA), AG/RES. 2807 (XLIII-O/I3) aprobada el 6 de junio de 2013.

- Bainham, Andrew (1999) "Parentage, Parenthood and Parental Responsibility: Subtle, Elusive Yet Important Distinctions". Bainham, Andrew; Sclater, Schelley D. \& Richards, Martin (Eds.). What is a Parent? A Socio-Legal Analysis. Hart Publishing, Oxford, Portland Oregon, 25-46 pp.

- Benavente, Pilar (2013) "Identidad y contexto inmediato de la persona (Identidad personal, el nombre de la persona, identidad 
sexual y su protección)". Anuario de la Facultad de Derecho de la Universidad Autónoma de Madrid, No 17, pp.105-161.

- Benavente, Pilar (2013) "Orientación sexual e identidad de género y relaciones jurídico privadas", Revista General de Derecho Constitucional, No $17,1-75$ pp.

- Bernal, Julia (2011) "Estados intersexuales en menores de edad: los principios de autonomía y beneficencia”, Revista de Derecho, No 36, 53-85 pp., p.70.

- Choudhry, Shazia and Herring, Jonathan. (2010) European Human Rights and Family Law. Hart Publishing, Oxford, Portland Oregon, 170-205 pp.

- Comisión Interamericana De Derechos Humanos (CIDH), Estudio elaborado por la Comisión Interamericana de Derechos Humanos "CIDH" en cumplimiento de la resolución AG/RES. 2653 (XLI-O/11): Derechos Humanos, Orientación Sexual e Identidad de Género, 23 de abril de 2012.

- Comité De Derechos Del Niño, Observación general No 14 "Sobre el derecho del niño a que su interés superior sea una consideración primordial (artículo 3, párrafo 1)", CRC/C/GC/14, 29 de mayo de 2013.

- Comité De Derechos Del Niño, Observación general No 5 "Sobre las medidas generales de aplicación de la Convención sobre los Derechos del Niño (articulos 4 y 42 y párrafo 6 del artículo 44)”, 27 de noviembre de 2003, CRC/GC/2003/5.

- Comité De Derechos Del Niño, Observación General No 12 "El derecho del niño a ser escuchado", 20 de julio de 2009, CRC/C/ CG/12.

- Consejo De Derechos Humanos De Naciones Unidas. Derechos Humanos, orientación sexual e identidad de género, de 14 de julio 2011, A/HRC/RES/17/19.

- Corral, Hernán (2007) "Identidad sexual y transexualismo. Desafíos para el Derecho de la persona y de la familia". Revista de Derecho y Ciencias Penales, No 9, 79-85 pp., p.5.

- Couso, Jaime (2006) "El Niño como Sujeto de Derechos y la Nueva Justicia de Familia. Interés Superior del Niño, Autonomía Progresiva y Derecho a Ser Oído", Revista de Derechos del Niño. No Tres y Cuatro. Santiago de Chile: UNICEF, 145-166 pp., p.147.

- EekelaAr. John (2005) “Deciding for Children". 7 Australian Journal of Professional and Applied Ethics, pp. 66-82, p. 66.

- Fernández, Silvia (2012) "La realización del proyecto de vida autorreferencial. Los principios de autonomía y desjudicialización”, La Ley, 13-25 pp., p.25. 
- Fernández, Carlos (1992). Derecho de la Identidad Personal, Buenos Aires, Astrea. 489 pp.

- Jenkins, R. (2004) Social Identity, London, Routledge. 218 pp.

- Macdonald QC, Alastair. (2011) The Rights of the Child: Law and Practice, Bristol: Family Law. 1232 pp., p. 460.

- Medina, Graciela (2012) "Comentario exegético a la Ley de Identidad de Género", La Ley, mayo, 45-57 pp., p.51.

- Newell, P. and Hodgrin, R. (2008) Implementation Handbook for the Convention on the Rights of the Child, 3rd. Edition, Suiza. UNICEF. 206 pp., p. 115.

- Rivero, Francisco (2010) "De la relación fáctica a la categoría jurídica: la figura del padrastro y madrastra", Revista de Magister y Doctorado en Derecho de Facultad de Derecho de la Universidad de Chile, No4, 163-188 pp.

- Von Stritzky, Johannes (2013) "El Desarrollo de la Protección Jurídica de las Personas Homosexuales, Bisexuales, Transexuales e Intersexuales (LGBT) en Alemania". Revista General de Derecho Constitucional, No 17, 1-29 pp.

\section{Jurisprudencia Citada}

- "Chaspky v Wood" (1881) 26 Kan. 650.

- "Fv F" [1902] 1 Ch 688.

- "K.B. v. J.R.”, 26 Misc. 3d 465, 887 N.Y.S.2d 516 Sup. Ct. Kings Co., NY 2009.

- "Re K" (Minors) (Wardship: Care and Control) [1977] 1 A11 ER 647.

- "Re McGrath (Infants)" [1883] 1 Ch 143.

- "S (BD) v S (DJ)" (Infants: Care and Consent) [1977] 1 A11 ER 656.

- "Ward v Laverty and Another" [1925] AC 101.

- CORTE IDH, Fondo, Reparaciones y Costas. Sentencia 12 de febrero de 2012, "Caso Atala Riffo y Niñas vs. Chile".

Disponible en http://www.corteidh.or.cr/docs/casos/articulos/ seriec_239_esp.pdf [fecha de visita: 25 de agosto de 2014].

- CORTE IDH, Fondo, Reparaciones y Costas. Sentencia de 27 de abril de 2012, "Caso Forneron e hija vs. Argentina".

Disponible en http://www.corteidh.or.cr/docs/casos/articulos/ seriec_242_esp.pdf [fecha de visita: 25 de agosto de 2014].

- House of Lords, Re G (Children), (2006), UKHL 43.

- Tribunal Europeo de Derechos Humanos. 1 de junio de 2004. Demanda No 45582/99. "Case Lebbink v. The Netherlands". 
Disponible en http://hudoc.echr.coe.int/sites/eng/pages/search. aspx?i=001-61799\#\{“itemid":[“001-61799”]\} [fecha de visita: 25 de agosto de 2014].

- Tribunal Europeo de Derechos Humanos. 26 de mayo de 2004. Demanda 74969/01. "Case Görgülü v. Germany".

Disponible en http://hudoc.echr.coe.int/sites/eng/pages/search. aspx?i=001-61646\#\{“itemid":[“001-61646”]\} [fecha de visita: 25 de agosto de 2014].

- Tribunal Europeo de Derechos Humanos. 11 de julio de 2002. Demanda No 25680/94. "Case I vs. United Kingdom".

Disponible en http://hudoc.echr.coe.int/sites/eng/Pages/search.as px\#\{"languageisocode":["ENG”],"documentcollectionid2": ["JU DGMENTS”],"kpdate":[“2002-07-11T00:00:00.0Z”,"2002-0711T00:00:00.0Z"],"itemid":[“001-60595"]\} [fecha de visita 25 de agosto de 2014].

- Tribunal Europeo de Derechos Humanos. 30 de noviembre de 2010. Demanda No 35159/09. "Case P.V. vs. Spain".

Disponible en http://hudoc.echr.coe.int/sites/eng/Pages/search. aspx\#\{“itemid":[“001-102597”]\} [fecha de visita: 25 de agosto de 2014].

- Sentencia Décimo Sexto Juzgado Civil de Santiago, de 30 de noviembre de 2009, Rol 09-2009.

- Sentencia Primer Juzgado Civil de Rancagua, de 16 de agosto de 2011, Rol 419-2010.

- Sentencia Corte de Apelaciones de Valparaíso, de 23 de julio de 2013, Rol 949-13.

- Sentencia Corte de Apelaciones de Santiago, de 21 de agosto de 2013, Rol 204-2012. 